\title{
Uterine vascular lesions: a rare cause of abnormal uterine bleeding, reporting of two cases
}

\author{
Sunita Arora ${ }^{1}$, Rupneet Kaur ${ }^{1 *}$, Anju Huria ${ }^{1}$, Ajay Gupta ${ }^{2}$ \\ ${ }^{1}$ Department of Obstetrics and Gynaecology, Government Medical College and Hospital, Chandigarh, Punjab, India \\ ${ }^{2}$ Department of Intervention Radiology, PGIMER, Chandigarh, Punjab, India
}

Received: 18 May 2014

Accepted: 10 June 2014

*Correspondence:

Dr. Rupneet Kaur,

E-mail: drrupneet@gmail.com

(C) 2014 Arora S et al. This is an open-access article distributed under the terms of the Creative Commons Attribution Non-Commercial License, which permits unrestricted non-commercial use, distribution, and reproduction in any medium, provided the original work is properly cited.

\begin{abstract}
Uterine vascular lesions in the form of arteriovenous malformation or pseudo aneurysm are rare but potential lifethreatening source of bleeding. A high index of suspicion and accurate diagnosis of the condition in a timely manner are essential because instrumentation that is often used for other causes of uterine bleeding can lead to massive hemorrhage. We describe two cases of uterine vascular malformation, one presenting as postabortal hemorrhage and other as postpartum hemorrhage. Case one presented as postabortal hemorrhage after induced abortion following dilatation \& curettage. Case two presented as delayed postpartum hemorrhage after six weeks following cesarean section. In both cases diagnosis of uterine arteriovenous malformation was made on Doppler ultrasonography which was subsequently confirmed on pelvic angiography. The embolization of affected uterine arteries was performed successfully in both cases. Uterine vascular lesion should be suspected in patient with abnormal vaginal bleeding, especially who has recent medical history of induced abortion or dilatation and curettage or cesarean section and so on. Although angiography remains the gold standard for making diagnosis, Doppler ultrasonography is also a good noninvasive technique for the same. Uterine artery embolization offers a safe and effective treatment.
\end{abstract}

Keywords: Uterine arteriovenous malformation, Doppler ultrasonography, Uterine artery embolization

\section{INTRODUCTION}

Female pelvis is one of the important locations of occurrence of vascular malformations which is of utmost importance. Unexplained, intermittent and torrential bleeding from female genital tract signifies the importance of diagnosing these malformations. Uterine vascular lesions arising from uterine artery e.g. Arteriovenous Malformation (AVM) is a rare phenomenon. Uterine trauma is one of the leading causes for development of uterine artery vascular lesions in the form of acquired Arteriovenous Malformation (AVM) or pseudo aneurysm. ${ }^{1-5}$ So far nearly 100 cases of uterine AVM and very few cases of pseudo aneurysm have been reported.
Trauma, resulting from prior dilation and curettage $(\mathrm{D} \& \mathrm{C})$, therapeutic abortion, uterine surgery, or direct uterine trauma may lead to development of acquired uterine AVMs. ${ }^{6}$ Same etiology can give rise to development of uterine artery pseudo aneurysm. Arterial embolization should be considered as the definitive treatment in such cases. We are reporting two cases of torrential vaginal bleeding after gestational events which were diagnosed to have uterine artery vascular lesions and underwent uterine artery embolization.

\section{CASE REPORT}

\section{Case 1}

A 22 years old lady with one previous child was referred to our hospital in gynaecology emergency with complains 
of profuse bleeding. She had 12 weeks amenorrhea following which she had incomplete abortion after attaining trauma due to fall from height. She underwent D\&C twice for incomplete abortion at an interval of 5 days because of excessive bleeding and suspicion of incomplete abortion. Twenty days after last D\&C she had third episode of excessive bleeding per vaginum. She was referred with the transfer note of incomplete abortion for further management. At the time of admission she was pale and had tachycardia. Her blood pressure was normal and she was not actively bleeding (per vaginum). Her gynecological examination didn't reveal any abnormal findings. On evaluation she was found to have negative urine pregnancy test and haemoglobin of $6 \mathrm{~g} / \mathrm{dl}$. Rest all blood investigations were within normal limits. Transvaginal sonography findings revealed multiple small cystic spaces confined to anterior wall of uterus with an empty uterine cavity and cervical canal. Doppler evaluation of the same lesion showed bunch of vessels with a high velocity and low resistance flow indicative of arteriovenous malformation (Figure 1). She was transfused 2 units of blood. During hospital stay she had another episode of massive haemorrhage and was taken up for angiography. Angiography revealed bilateral normal internal and external iliac vessels with leash of vessels arising from both right and left uterine arteries (Figure 2, Figure 3). Both abnormal vessels were embolized using 500-700 micron PVA particles. Post embolization angiogram showed no abnormal vessels. After embolization patient remained asymptomatic and was discharged in satisfactory condition after 5 days of observation. She was followed up in outpatient clinic afterwards. Patient resumed her normal menstrual cycle 1 month later and is having regular cycles with normal flow and is asymptomatic till 2 years of follow up.

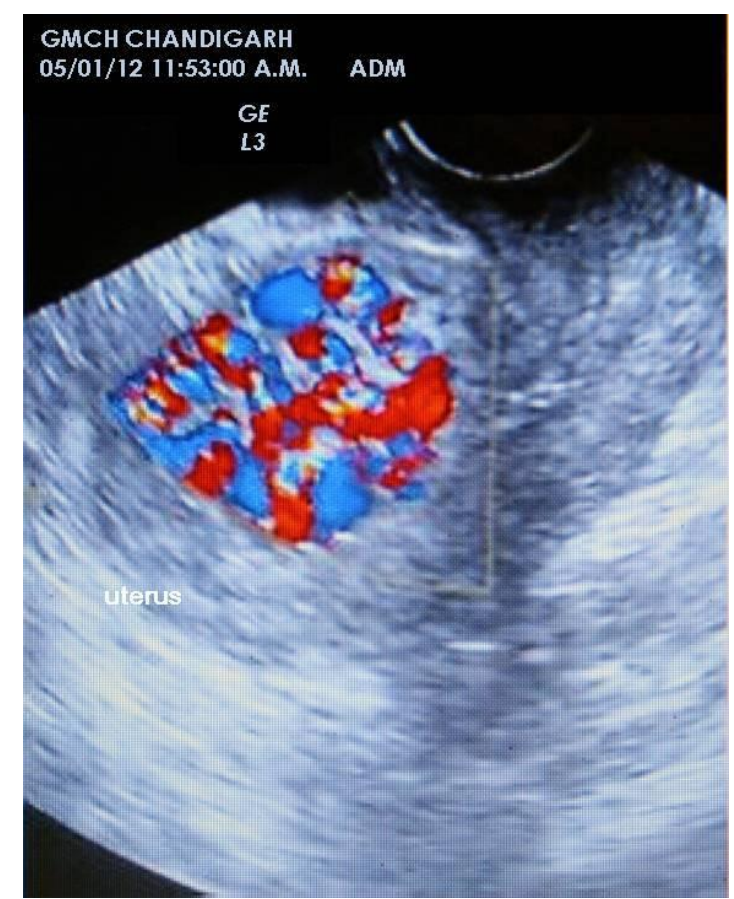

Figure 1: Doppler imaging of uterus.

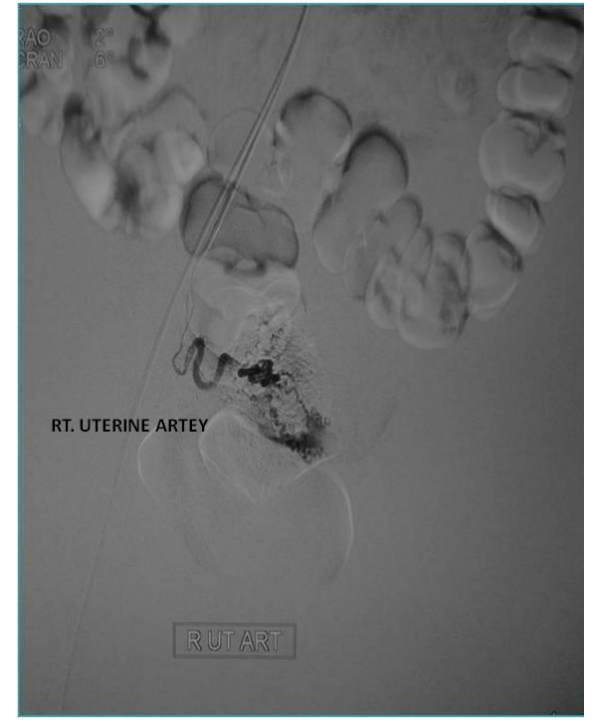

Figure 2: Angiogram showing abnormal vascular pattern, right uterine artery.

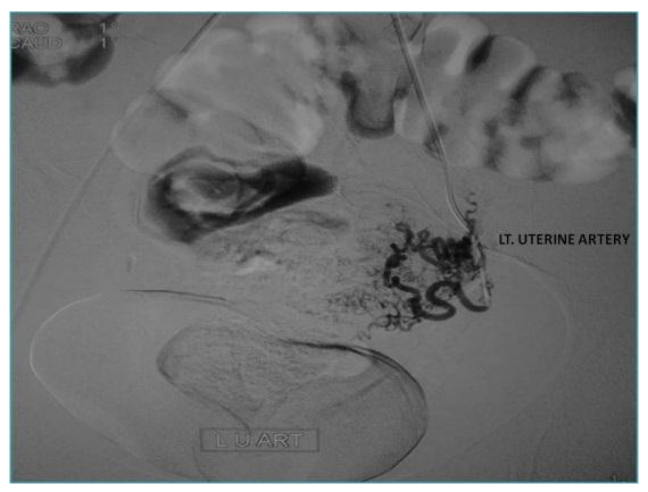

Figure 3: Angiogram showing abnormal vascular pattern, left uterine artery.

Case 2

A thirty years old lady was referred to our hospital with second episode of bleeding per vaginum on postoperative day 42 of emergency cesarean section for breech presentation. On postoperative day 14 she had her first episode of bleeding which continued for 1 week. There had no intraoperative or postoperative complications as per her records. On admission two units of whole blood were transfused. Her pelvic ultrasound showed a normal sized uterus with an empty endometrial cavity. On Doppler evaluation an arteriovenous malformation was revealed at the scar site (Figure 4, Figure 5). Interventional radiology was sought as the patient was young and desired future fertility.

Angiography revealed a left arteriovenous malformation with a coexistent pseudo aneurysm with extravasation of contrast into the uterine cavity (Figure 6). Left uterine artery embolization was done using 400-600 $\mu \mathrm{m}$ poly vinyl alcohol (PVA, Cook) particles. Patient was asymptomatic in postoperative period. She resumed her 
normal menstrual cycle 3 months later and is having regular cycles with normal flow and is asymptomatic till 1 year of follow up.

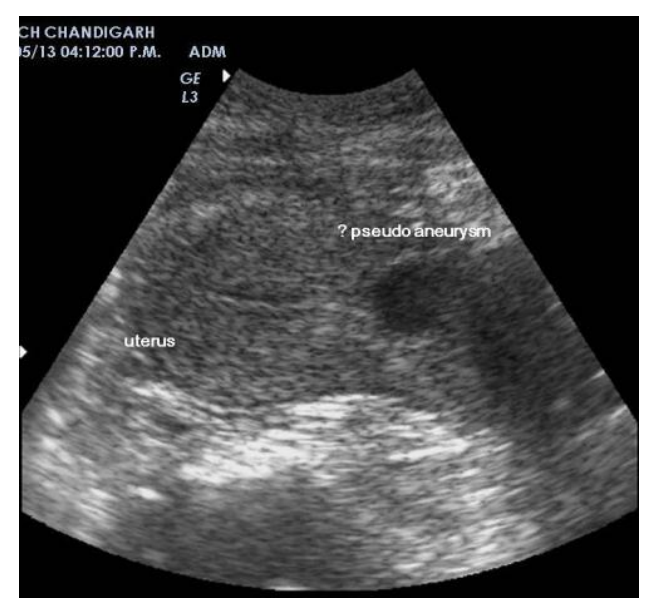

Figure 4: D imaging of uterus.

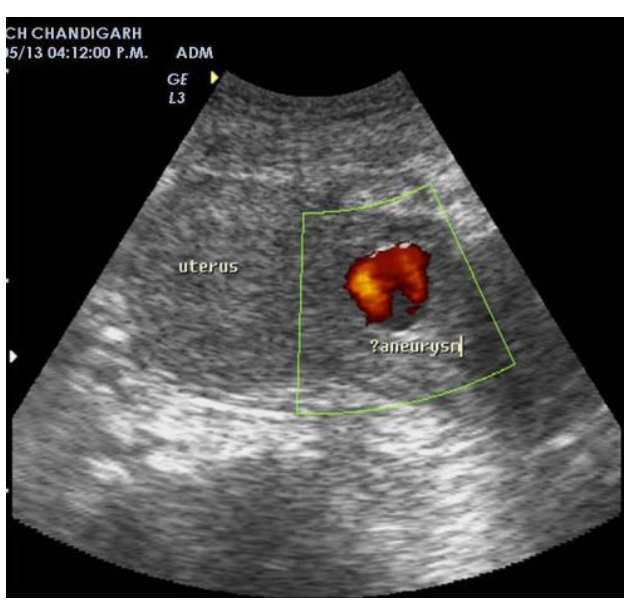

Figure 5: Doppler imaging of uterus.

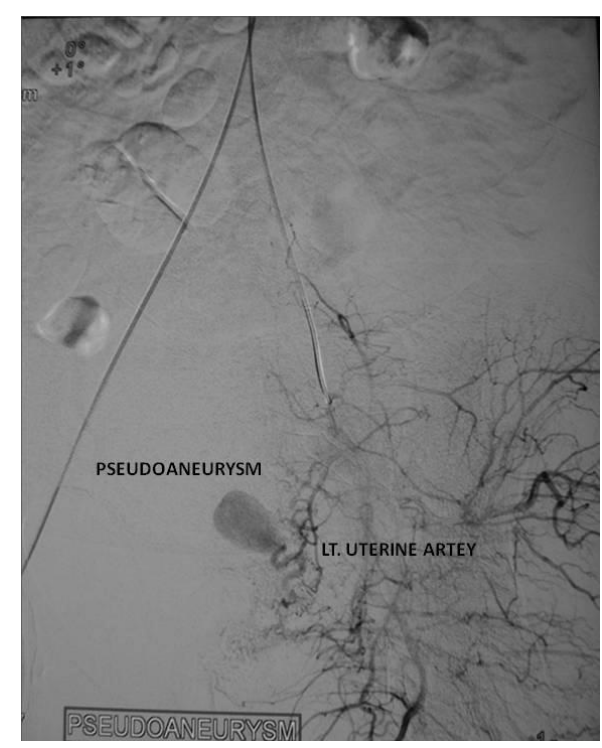

Figure 6: Angiogram showing abnormal vascular pattern, left uterine artery.

\section{DISCUSSION}

Uterine vascular lesions, though rare, are characteristically life-threatening because of potential for causing profuse uterine bleeding. Till date numerous cases of uterine arteriovenous malformations have been reported under the terminologies uterine 'haemangioma', 'arteriovenous fistula', 'pseudo aneurysm' etc. ${ }^{7}$ A proportion of these cases had reported spontaneous resolution of the lesions. Most of the cases have been reported as having uterine arteriovenous malformation. Discrepancy in sonological findings, histopathologic correlation and management (need of embolization) of these lesions exists as reported by Rufener et al. ${ }^{8}$ Hence it seems logical to categorize these lesions with nomenclature 'uterine vascular lesion' as suggested by Vijaykumar et al. ${ }^{7}$ So far there is no defined universal classification of uterine arteriovenous malformations / vascular lesions. We have used the term 'uterine vascular lesion' for broadly describing these lesions. Acquired uterine AVM \& pseudo aneurysm are variants of uterine vascular lesions.

A prompt diagnosis and treatment is very important as patients with this presentation are usually misdiagnosed as cases of incomplete abortion and treating doctor tends to do a therapeutic curettage, which can aggravate uterine bleeding. Hence, early identification and initiation of treatment for uterine vascular lesions is essential for a good patient outcome.

In the past, traditional treatment of patients with uterine arteriovenous malformations and vaginal bleeding was vascular ligations (e.g. bilateral internal iliac artery or uterine artery ligation) or by surgical hysterectomy. Internal iliac artery ligation though, preserves the uterus, has a potential disadvantage in the form of development of rich collateral vessels in pelvic organs which may cause re-bleeding. ${ }^{9}$ With the advent of angiographic techniques, ligation of the internal iliac artery is seldom used now these days. Currently, with the recent development of pelvic artery angiography and selective uterine artery embolization techniques, this approach has become more popular and accepted approach for treatment of uterine vascular lesions.

Rarely, uterine AVMS may present as post abortal hemorrhage incidence being 0.1 to 21 per thousand cases. $^{10}$ Though, common causes of postabortal haemorrhage are cervical or vaginal lacerations, uterine perforation, retained tissue, uterine atony, infection, abnormal placental implantations (including placenta previa, accreta, increta and percreta), coagulopathy but very rarely, uterine arteriovenous malformation can lead to major catastrophe. Halperin R et al. reported 3 cases of uterine AVMs after early missed and induced abortions. ${ }^{11}$ Unlike the more common causes of excessive uterine bleeding it may be aggravated by D\&C. The treatment approach in terms of uterine artery embolization in postabortal haemorrhage for uterine AVM has been supported by few case reports. Yang et al. ${ }^{2}$ has reported 
seven patients with post abortal haemorrhage following second trimester termination, successfully treated with uterine artery embolization.

In cases with hemodynamically stable status, estrogens and progestins, methylergonovine maleate, danazol, 15methyl-prostaglandin F2 $\alpha$, oral contraceptives, and Gonadotropin-releasing hormone agonist therapy has been used for long term management. ${ }^{12-14}$

Montanari et al. ${ }^{15}$ reported the use of intravenous conjugated estrogens and oral methylergometrine maleate in symptomatic patient with AVM.

Similar to clinical presentation of postabortal hemorrhage, uterine pseudoaneurysm may present as a rare entity which can cause life-threatening 'delayed' postpartum hemorrhage. 'Pseudoaneurysm' has been classified as one of the variant of uterine vascular lesions. Our second case presented as late postpartum (postoperative) hemorrhage with uterine artery pseudoaneurysm. Pelage et al. and Zimon AE et al. in two different studies reported uterine artery pseudoaneurysm as cause of secondary post-partum haemmorhage. $^{16,17}$ Pseudoaneurysms are a known complication of vascular injury. ${ }^{17,18}$ Uterine incision at the time of cesarean delivery subjects the uterine artery to arterial wall injury. It is hypothesized that after arterial injury, blood dissects along the arterial wall which leads to collection of blood in the perivascular space. Communication of collected blood with the injured vessel forms a pseudoaneurysm. Extraluminal turbulent blood flow causes the false aneurysm to enlarge, making it susceptible to rupture. ${ }^{19}$ Pseudoaneurysms or false aneurysms differ from true aneurysms in that they are not surrounded by the three layers of the arterial wall. Prompt recognition and management are critical in severe vaginal bleeding. The initial management of uterine artery pseudo aneurysm postpartum hemorrhage requires aggressive resuscitation. Uterine arterial pseudo aneurysm rupture is an infrequent, life-threatening cause of delayed postpartum hemorrhage requiring prompt diagnosis and treatment. An alternative approach to therapy that is effective in the emergency consists of vaginal packing using gauze to achieve tamponade. Other methods of tamponade can also be opted for transient measure for prevention of blood loss. ${ }^{20,21}$

In the past, the majority of uterine artery pseudo aneurysms were treated with hysterectomy, with or without hypogastric artery ligation. ${ }^{22}$ In recent years, uterine artery embolization has emerged as treatment modality for controlling bleeding resulting from vascular malformations and various other etiologies of postpartum hemorrhage. $^{23}$

Conclusively, arterial embolization has distinct advantages for being selected as definite treatment modality for torrential bleeding due to uterine AVMs. But adequate resuscitation of the patient from hemorrhagic - hypovolemic shock, prompt diagnosis with imaging and avoiding unnecessary uterine surgical procedures (e.g. D\&C) are the key points for patient's successful outcome. Potential benefits of arterial embolization are that it is less invasive and does not require general anesthesia in a potentially unstable patient. With angiography it is easy to identify the source of bleeding, leading to rapid control of the hemorrhage, a low incidence of re-bleeding, and a high success rate.

\section{CONCLUSION}

Uterine vascular lesions should be suspected in women who present with abrupt, profuse uterine bleeding with a history of surgical abortion or with delayed postpartum hemorrhage. Patients of such profile should be considered for uterine artery embolization and prompt measures should be opted for resuscitation.

\section{Funding: No funding sources \\ Conflict of interest: None declared \\ Ethical approval: Not required}

\section{REFERENCES}

1. Timmerman D, Van den Bosch T, Peeraer K, et al. Vascular malformations in the uterus: ultrasonographic diagnosis and conservative management. Eur J Obstet Gynaecol Reprod Biol. 2000;92(1):171-8.

2. Yang JJ, Xiang Y, Wan XR, Yang XY. Diagnosis and management of uterine arteriovenous fistulas with massive vaginal bleeding. Int J Gynaecol Obstet 2005;89(2):114-9.

3. Maleux G, Timmerman D, Heye S, Wilms G. Acquired uterine vascular malformations: radiological and clinical outcome after transcatheter embolotherapy. Eur Radiol. 2005;16:299-306.

4. Jain KA, Gerscovich EO. Sonographic spectrum of pelvic vascular malformations in women. J Clin Ultrasound. 1999;27(9):523-30.

5. Kwon JH, Kim GS. Obstetric iatrogenic arterial injuries of the uterus: diagnosis with US and treatment with transcatheter arterial embolization. Radiographics. 2002;22(1):35-46.

6. Huang MW, Muradali D, Thurston WA, Burns PN, Wilson SR. Uterine arteriovenous malformations: gray scale and Doppler ultrasound features with MR imaging correlation. Radiol. 1998;206:115-23.

7. Vijayakumar A, Srinivas A, Chandrashekar BM, Vijayakumar A. Uterine vascular lesions. Rev Obstet Gynaecol. 2013;6(2):69-79.

8. Rufener SL, Adusumilli S, Weadock WJ, Caoili E. Sonography of uterine abnormalities in postpartum and postabortion patients: a potential pitfall of interpretation. J Ultrasound Med. 2008;27:343-8.

9. Michael LP, Caroline AB. Percutaneous transcatheter embolization for control of lifethreatening pelvic hemorrhage from gestational trophoblastic disease. Obstet Gynaecol 1992;80:5714. 
10. Henshaw SK. Unintended pregnancy and abortion: a public health perspective. In: Paul M, Lichtenberg ES, Borgatta L, Grimes DA, Stubblefield PG, eds. A Clinician's Guide to Medical and Surgical Abortion. 1st ed. New York: Churchill Livingston; 1999: 1122.

11. Halperin R, Schneider D, Maymon R, Peer A, Pansky M, Herman A. Arteriovenous malformation after uterine curettage: a report of 3 cases. J Reprod Med. 2007;52:445-9.

12. Manolitsas T, Hurley V, Gilford E. Uterine AVM: a rare cause of uterine haemorrhage. Aust NZ J Obstet Gynaecol. 1994;34:197-9.

13. Elia G, Counsell C, Singer SJ. Uterine artery malformation as a hidden cause of severe uterine bleeding; a case report. J Reprod Med. 2001;46:398400.

14. Nonaka $\mathrm{T}$, Yahata $\mathrm{T}$, Kashima K, Tanaka K. Resolution of uterine arteriovenous malformation and successful pregnancy after treatment with a gonadotropin-releasing hormone agonist. Obstet Gynaecol. 2011 Feb;117(2 Pt 2):452-6.

15. Montanari L, Alfei A. Arteriovenous malformation of the uterus: successful pregnancy after medical treatment. Ultrasound Obstet Gynaecol. 2007;30:585.

16. Pelage JP, Soyer P, Repiquet D et al. Secondary postpartum haemorrhage: treatment with selective arterial embolization. Radiol. 1999;212:385-9.
17. Zimon AE, Hwang JK, Principe DL, Bahado-Singh RO. Pseudoaneurysm of the uterine artery. Obstet Gynaecol 1999;94:827-30.

18. Bromley PJ, Clark T, Weir IH, Zwirewich CV. Radiologic diagnosis and management of uterine artery pseudoaneyrysm: case report. Can Assoc Radiol J. 1997;48:119-22.

19. Bhatt A, Odujebe O, Bhatt S, Houry D. Uterine artery pseudoaneurysm rupture: a life-threatening presentation of vaginal bleeding. Ann Emerg Med. 2010;55:460-3.

20. Georgiou C. Balloon tamponade in the management of postpartum haemorrhage: a review. BJOG. 2009;116:748-57.

21. Schlicher NR. Balloon compression as treatment for refractory vaginal hemorrhage. Ann Emerg Med. 2008;52:148-50.

22. Descargues G, Douvrin F, Gravier A et al. False aneurysm of the uterine pedicle: an uncommon cause of post-partum haemorrhage after caesarean section treated with selective arterial embolization. Eur J Obstet Gynaecol Reprod Biol. 2001;97:26-9.

23. Kwon JH, Kim GS. Obstetric iatrogenic arterial injuries of the uterus: diagnosis with US and treatment with transcatheter arterial embolization. Radiographics. 2002;22:35-46.

DOI: 10.5455/2320-1770.ijrcog20140901

Cite this article as: Arora S, Kaur R, Huria A, Gupta A. Uterine vascular lesions: a rare cause of abnormal uterine bleeding, reporting of two cases. Int J Reprod Contracept Obstet Gynecol 2014;3:749-53. 